\title{
The genesis of vandalism: From childhood to adolescence
}

\author{
Irina V. Vorobyeva, Olga V. Kruzhkova , Marina S. Krivoshchekova \\ Ural State Pedagogical University, Ekaterinburg, Russia
}

${ }^{\star}$ Corresponding author. E-mail: galiat1@yandex.ru

\begin{abstract}
This study was developed because vandal behavior is an increasing threat in the world. Countries, commercial companies, and individuals experience great damage to property as a result of individual vandal acts. In addition, vandalism threatens not only "tangible assets" but also the cultural and historical heritage of modern humanity. Despite the threatening spread of vandalism, the study of its psychological foundations, including its origins, in the context of individual life courses is in many ways terra incognita. The objective of the present study was to investigate the genesis of vandal behavior and the sociopsychological and individual personality factors in the formation of readiness to destroy public property and the property of others. A comprehensive study of children, adolescents, and young adults $(N=1522)$, as well as of their social environment, revealed mechanisms of the readiness to commit vandal acts that were present since childhood. The study was conducted by examining four age groups: preschoolers (4-6 years), primary school pupils (7-9 years), adolescents (12-15 years), and young adults (17-22 years); the instruments used were specific-age batteries, observation, expert techniques, and questionnaires. We found that the characteristics of parent-child relationship are is the basis for forming the boundaries of the permissible activity of the child; disturbance in the parent-child relationship can lead to the development of forms of vandalism in children. We describe the specificity and intensity of the vandal activity of adolescents and young adults in the context of their environment, and we look at the individual characteristics that promote deviant behavior. Thus, vandal activity is not only a specific characteristic of adolescents and young adults, and it is not always very destructive. Basic vandal activity originates in the early stages of ontogenesis as a result of a deformation in social interaction that becomes fixed and converted into the destructive actions of people trying through this form of activity to understand themselves in social space.
\end{abstract}

Keywords: vandalism, genesis of vandal behavior, preschool age, primary school age, adolescence, youth, personality and environmental factors in the development of vandal behavior 


\section{Introduction}

Human beings are the only creatures on the planet who consciously and deliberately alter the space around them. As a result of human activity the made environment is created. But the desire for change does not end with creating this environment; people continue to change it: they do not accept the fact that it is already given as a result of others' actions. By itself, the transformation of the environment can be both socially approved and socially disapproved - that is, of a vandal character. What is the reason for this particular type of activity, its deep motivation, its basic requirements?

On the one hand, this activity can be regarded as the result of an attempt to transform, create, innovate, or change, or to provide social or spiritual benefits to oneself or other people. On the other hand, the reason for this type of activity may lie deeper: a person may not transform the environment in a positive way but may break it down. We call graffiti on walls offensive, obscene, or simply informative or even decorative, but carving on fences, rocks, the bark of trees, benches is nothing more than the unauthorized destruction or modification of the property of others or public property (Vorobyeva \& Kruzhkova, 2012). This is not just a problem with the self-expression or defects of upbringing of some individuals. Who of us didn't write on the desk at school? But why did we do it? Because of boredom, as a protest, or as the result of a special inner need that we did not express in other ways? It is possible to answer these questions by means of complex psychological research that considers vandalism not only when it occurs but also as a result of its genesis previously.

However, there are only a few studies of this question. A small number of publications concerning vandal behavior have focused on aspects of legal regulation and criteria for qualifying destructive actions as vandalism (for example, Harina, 2005; Pashutina, 2009; Shuruhnov, 2002) as well as on statistics and methods of combating the spread of vandalism in some countries or areas of life (for example, Ceccato \& Haining, 2005; Pirozhkov, 1994; Shvets \& Yakovlev, 2011; Thompson et al., 2012). The number of studies of the psychological bases of vandalism, its personal and environmental determinants, its forms and manifestations, its motives is quite small (for example, Allen \& Greenberger, 1978; Coffield, 1991; Cohen, 1973; Goldstein, 1996; Skorokhodova, 1999); such studies are centered mainly on the evaluation of possible preventive actions (for example, Kalmikova, 2013; Patrusheva, 2010; Skorokhodova, 1999; Vatova, 2007). One feature of the modern study of vandalism in psychopedagogical practice is the relatively limited focus of interest of researchers on the adolescence and early adulthood of vandals (Gurova, 2014; Samokhina, 2007; Tserkovnikova, 2011; Vatova; 2000) without taking into account its genesis in childhood. At the same time, the consideration of the specifics of vandalism in different age periods will not only create a more accurate picture of the forms and embodiments of such activity but also help to identify predictors of the formation of a vandal model of behavior. This is a necessary basis for the effective prevention of destructive behavior because the already-established and implemented strategy of dealing with vandalism by directives and judgmental methods brings only a short-term effect, as vandals will always find a way to express their desire for the destruction of private or public property. 
Elements of the destructive activity of a person appear in early childhood. But at this age destruction is a method of gaining knowledge of the laws and the characteristics of the material world, the subjective environment. Despite the result, which can be very close to vandalism, the child never considers this behavior as destructive and antisocial because, for young children, the limits of acceptable activity are yet to be determined and socially prescribed.

Later, during the preschool years, vandal actions can be a way of studying the material aspects of the environment, of understanding the mechanisms of the behavior of other people and their reactions to the destructive behavior, and of determining manipulative possibilities to control the behavior of others. A preschooler builds a prosocial behavior model by reflecting on the reactions of other people, both adults and peers, to destructive behavior. However, excessive destructive activity of a vandal character is seen here more as the result of a lack of education than as a personal choice of the child.

When a child goes to school, vandal actions are often random, when children, because of their lack of experience, cannot predict the outcome of their actions, which can be protective mechanisms for the release of tension and stress arising from educational or communication failure or excessive psychological pressure from the social environment.

Teenagers, whom many authors consider the main perpetrators of vandalism (Elliott, Huizinga, \& Menard, 1989; LeBlanc \& Freshette, 1988; Pirozhkov, 1994; Vatova, 2007; Vorobyeva \& Kruzhkova, 2014), are quite often prone to destructive actions against a stranger or public property. Almost all teenagers engage in these small vandal acts in their communicative environment, without ascribing to them vandal values. Because the motivational bases of vandal activity are varied and numerous, the choice of this model can be determined by a combination of personal and environmental factors. However, the role of each of these predictors to date is quite undefined and empirically not proven.

Adolescence is characterized by already realized vandal models of behavior that are either integrated into an overall deviant personality or embedded in the value-ideological component of personality that is formed by conditions of the interactions in subcultural space.

\section{Method}

The total sample of the study was 1,522 respondents ( $42 \%$-boys, $58 \%$-girls)in different age groups. These included preschoolers (65), primary school pupils (253), teens (448 middle school students), and young adults (466 students in institutions of secondary and higher education), also teachers and parents as experts in the assessment of children's behavior (5 expert educators, 10 expert class teachers, 65 parents of preschool children, 210 parents of children in primary school). All students in the study were not active vandals, but of the adolescents and young adults the majority noted that they had experience causing damage (major or minor) to public property or the property of others. The basic indicators reflect those of the normative sample in relation to the characteristics of the population. Because the participants were children from complete and incomplete (brought up only by the mother) families, significant differences in the manifestation of 
willingness to vandal behavior between these categories of participants in the study were not revealed.

The research methods were a battery of diagnostic instruments, questionnaires, trace tests, and observation methods specific to each age group, as described in the following sections.

\section{Preschoolers}

1. Our protocol for observing the child's play. This protocol is aimed at determining the characteristics of the child's interaction with the world of things in the process of communication with peers. It assesses the manifestation of certain types of motivational readiness of the child to perform destructive actions in relation to two types of objects: their things (toys) and other people's things or social things (toys). Valuations are based on a 5-point Likert scale, in which the maximum score corresponds to a high level of preparedness for engaging in destructive actions with the objects of the material world.

2. The Parental Attitude Research Instrument (PARI) of E. S. Schaefer and R. Q. Bell (adapted in Russia by T. V. Neshcheret). This diagnostic examines parental attitudes toward various aspects of family life (including toward their interaction with the child). The questionnaire consists of 115 claims, in response to which the respondent has an option to choose scale points from 4 "full agreement" to 1 "complete disagreement." The results are described by 23 aspects of parents' attitudes to the child and family life, including 8 aspects of their attitude toward family roles (parochialism of women within the family - the mother is concerned solely with the family; the mother has a sense of self-sacrifice; presence of family conflicts; superauthority of the parents; mother's dissatisfaction with the role of housewife; "indifference" of the father and his noninclusion in the affairs of the family; dominance of the mother; dependence and lack of independence of the mother) and 15 aspects of the parent-child relationship (verbal manifestations, verbalization; partnerships; development of the activity of the child; egalitarian relationship between parents and child; irritability, irascibility; severity, excessive rigor; avoiding contact with the child; excessive care, establishing a relationship of dependence; overcoming resistance, suppression of the child's will; creation of a sense of security; fear of offending the child; suppression of aggression; suppression of sexuality; excessive intervention in the child's world; desire to accelerate the development of the child). These 15 aspects are distributed according to the three major trends in the parent-child relationship: optimal emotional contact, excessive emotional distance, and excessive focus on the child.

3. The Parental Attitude Questionnaire of A. Ya. Varga and V. V. Stolin. This diagnostic consists of 49 statements about parental attitudes. Respondents express their agreement or disagreement with them. The description of the results is in accordance with the following scale: adoption/rejection of the child (an emotionally positive attitude toward the child indicates adoption; an emotionally negative attitude toward the child indicates rejection); cooperation (adults desire to cooperate with the child, they manifest genuine interest and involvement in the child's affairs); symbiosis (unity with the child, contact between the child 
and the adult); control (degree of democracy or authoritarianism in the adults' relationship with the child); attitude toward failure of the child (the adults' ability to assess the child's strengths and weaknesses, successes and failures).

4. The "Success" Program of I. A. Burlakova, E. E. Klopotova, and E. K. Yaglovskaya. This educational program is based on observation of the child and diagnostic tests. The technique diagnoses 9 integrative qualities of the child: curiosity; activity; emotional responsiveness; mastery of the means of communication and ways of interacting with adults and peers; ability to control behavior and to plan actions based on the primary value concepts; ability to observe basic common norms and rules of conduct; ability to solve intellectual and personal problemsat an appropriate age; mastery of the universal prerequisites for educational activity; mastery of the necessary skills and abilities.

\section{Primary school age}

1. A questionnaire that we devised to allow parents to identify the features of the child's interaction with things in the child's communication space. This instrument consists of 22 questions, the answers to which are placed on a Likert scale. All questions are divided into three blocks: they characterize the tendency of the child to destroy object, the child's preference for things belonging to others, and the child's desire for novelty in relation to personal things.

2. The Parental Attitude Research Instrument, as described above.

3. Methods for evaluating the parental relationship.

\section{Adolescents}

1. The questionnaire Personal Psychological Sovereignty of S. K. Nartova-Bochaver. This personality questionnaire consists of 80 statements formed into 6 scales: sovereignty of the physical body, sovereignty of the territory of things, theories and beliefs, habits, social relations, and human values. Respondents are asked to respond on a dichotomous scale (yes/no).

2. The profile Biography of Subjectivity of O. I. Motkov. This diagnostic consists of five blocks that can be used to identify the level of subjectivity of people of different ages on a Likert scale according to the following criteria: independence; activity; initiative; creativity; ability to manage emotions, desires, and actions; desire for self-development and self-organization; awareness of one's own personality; rationality; harmony of personality; pursuit of middle or high achievement.

3. The questionnaire Motives for Vandal Behavior of I. V. Vorobyeva, O. V. Kruzhkova, and S. A. Ostrikova. This instrument diagnoses 10 kinds of motives for vandal behavior: aggressive, tactical, caused by curiosity, mercenary, existential, aesthetic, as protest, caused by conformity, caused by inconvenience, environmental, caused by boredom. The questionnaire consists of 80 statements, each of which is evaluated by the respondents on a 4-point scale indicating their opinion of the admissibility or inadmissibility of such behavior. The questionnaire indicates a decrease or increase in the level of preparedness to commit vandal actions and highlights the main motive for destructive behavior. 


\section{Young adults}

1. The Subjective Control Inventory of E. Bazhin, E. Golynkina, and A. Etkind. This technique consists of 44 statements, to each of which the respondent expresses agreement or disagreement on a dichotomous scale (yes/no). The level of internality is diagnosed on the following scale: total internality, internality of achievements in the field of failures of the internal relations of production, internality in the field of interpersonal relationships, internality in health and disease, internality in family relations.

2. The questionnaire Personal Psychological Sovereignty, as described above.

3. The profile Biography of Subjectivity, as described above.

4. The questionnaire Motives for Vandal Behavior, as described above.

\section{Statistical analysis}

For the statistical analysis of the results of the research package we used IBM SPSS Statistics 19 and an additional module, AMOS. In order to solve research problems we used the following additional techniques:

- descriptive statistics to reflect general trends in the parameters of the respondents

- two-step cluster analysis to isolate from the total sample homogeneous groups with significant differences between them

- comparative analysis (the Mann-Whitney U test) to detect statistically significant differences between treatment subgroups in the main sample

- linear regression analysis to determine the personal and environmental predictors of readiness to engage in vandal behavior

- structural equation modeling to identify the overall structure of the relationship between and the interdependence of (1) environmental factors and individual personal characteristics of respondents and (2) indicators of readiness to engage in vandal behavior.

\section{Results}

The compilation and interpretation of data through the use of complex mathematical and statistical procedures and methods of qualitative analysis of the results made it possible to describe the particular manifestations of human activity in the context of the commission of any vandal actions in relation to private or public propertyin each of the studied age periods.

\section{Preschoolers}

Observation of play and communicative activities allowed us to estimate the incidence and manifestations of actions of a vandal character of each observed child. The main indicators were the beginning of play with the child's own and others' toys; these observations demonstrated the children's relationship to their own property as well as to others' property and to public property. To highlight the be- 
havior of different groups of children we carried out a two-step cluster analysis, which at a high confidence level divided the sample into two homogeneous subgroups. The first group comprised the $77 \%$ of the children who had adequately formed strategies of interaction with their own objects and the objects of others. The second group consisted of the $23 \%$ of the children who showed abnormal behavior in relation to their own, others', and common toys. Comparative analysis helped confirm the differences in the behavioral characteristics of the children in the selected groups. Thus, the following performance measures of the activity of children in the second group were statistically lower than those of children with adequate behaviors: reasonableness $(U=248.0 ; p=.036)$, harmoniousness of personality $(U=258.5 ; p=.055)$. In addition, for children in the second group the formation of integrative qualities was lower on the following parameters: mastery of the means of communication and ways of interacting with adults and peers $(U=277.5$; $p=.028)$, the presence of primary representations of themselves and of their families $(U=252.5 ; p=.007)$. Thus, the children who demonstrated vandal elements in their actions had difficulty communicating with peers and adults; were impulsive and often reacted inadequately in communicative situations (they were aggressive or, conversely, too timid); had a poor understanding of themselves and the motives for their actions; and may have had low levels of education for their age.

Through the use of regression analysis we obtained 4 models that describe the determination of the child's manifestations of vandal activity and the specificity of the boundaries of its distribution. Thus, the overall index of a child's vandal activity was dependent on the application or nonapplication by parents of the type of upbringing called "acceptance" (model parameters: $F=4.8 ; p=.032 ; R^{2}=17.1 \%$; $\beta=0.267$ ). That is, when a parent likes a child just as the child is, the parent respects the child's individuality, tends to spend much time with the child, approves of the child's interests and plans, and contributes to the initiative and creativity of the child to the extent that the child sees fit. Furthermore, this index was also detected in specific features of parental attitudes toward the child and the actual parentchild relationship (model parameters: $F=4.8 ; p=.000 ; R^{2}=40.6 \%$ ), in particular, the mother's development of a limited interest in the family $(\beta=0.404 ; p=.002)$, her dissatisfaction with the role of housewife $(\beta=0.331 ; p=.013)$, dominance of the mother $(\beta=0.258 ; p=.051)$, egalitarian relationship between parents and child $(\beta=0.392 ; p=.013)$, inhibition of the suppression of the child's will $(\beta=-0.368$; $p=.023)$, reduction in severity and excessive rigor $(\beta=-0.358 ; p=.007)$, decrease in the "indifference" of the father and his noninclusion in the affairs of the family $(\beta=-0.293 ; p=.036)$, restriction of excessive intervention in the child's world $(\beta=-0.289 ; p=.054)$.

Interestingly, the child's destructive activity toward the child's own things (model parameters: $F=4.8 ; p=.000 ; R^{2}=37.1 \%$ ) and toward the objects of others (model parameters: $F=4.9 ; p=.000 ; R^{2}=39.9 \%$ ) were determined by a single list of predictors: suppression of the child's aggression $(\beta=0.439, p=.011$; and $\beta=0.377, p=.048$, respectively), avoiding contact with the child $(\beta=0.293, p=.025$; and $\beta=0.323, p=.014$, respectively), dependence and lack of independence of the mother $(\beta=0.504, p=.000$; and $\beta=0.491, p=.000$, respectively), absence of the mother's sense of self-sacrifice $(\beta=-0.324, p=.000$; and $\beta=-0.610, p=.000$, respectively), avoiding excessive strictness and severity $(\beta=-0.244, p=.047$; and 
$\beta=-0.287, p=.020$, respectively), unwillingness to create an egalitarian relationship between parents and child $(\beta=-0.299, p=.041$ and $\beta=-0.272, p=.059$, respectively), and lack of desire to accelerate the child's development $(\beta=-0.275, p=.024$; and $\beta=-0.249, p=.040$, respectively).

Thus, the preschoolers' choice of strategies for interacting with objects in the environment depended on different elements of the child-parent relationship.

\section{Primary school age}

The questionnaires that were filled out by the parents of primary school pupils together with photos of each child's play space at home showed that the most characteristic feature of the study sample was the orientation of the pupils, in their attitudes toward the material objects in their environment, toward novelty $(M=2.5)$. Thus, the students could easily part with old things, did not worry about their loss or damage, and tended to like new objects. The borders of their activity in this regard were characterized by mobility; new objects were easily adopted, but there was no clear identification of their own things and those of others; this situation can provoke unauthorized use of objects and lead to the appearance of vandal activity. In this case, the integral measure of the tendency of the pupils to commit van-

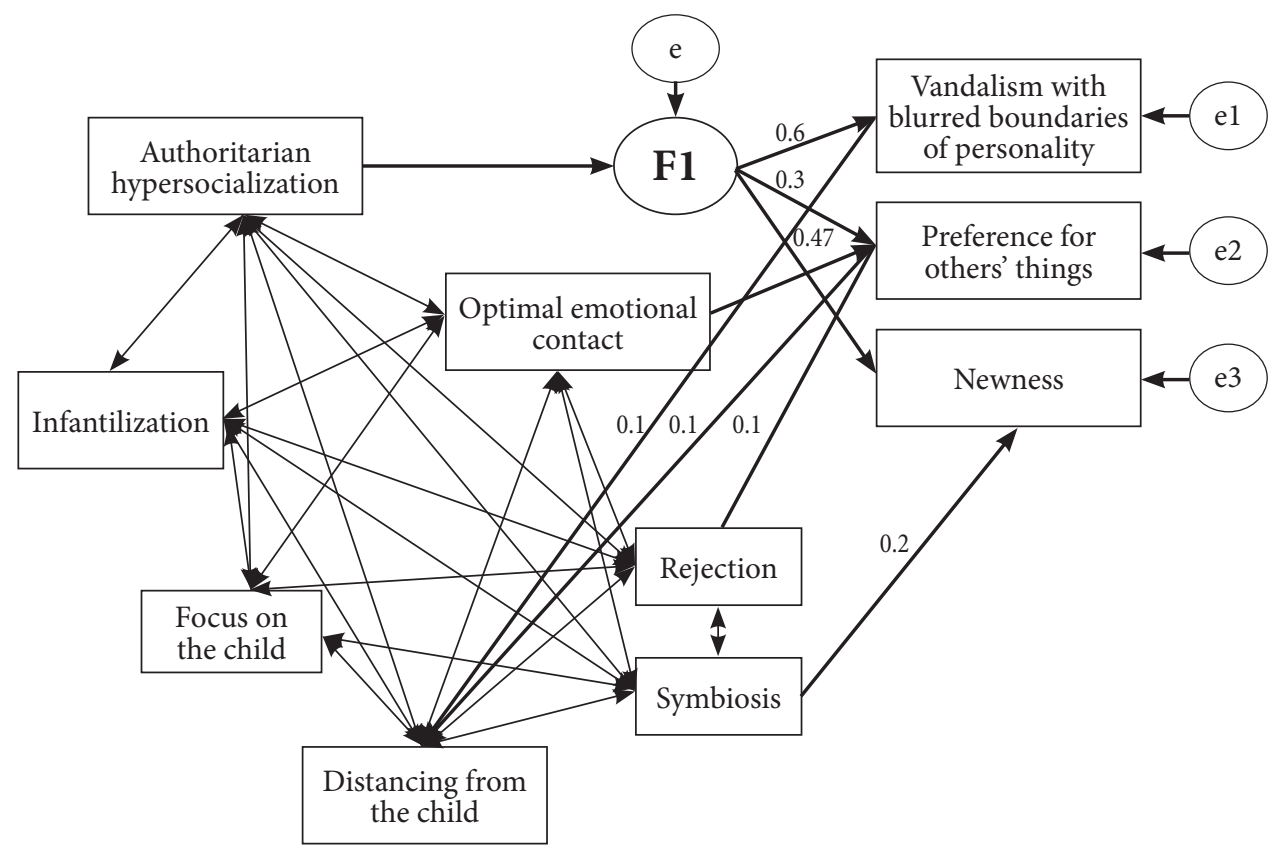

Figure 1. Measurement model of the connections between features of the parent-child relationship and indicators of the child's relationship to objects in the material world (Vorobyeva \& Kruzhkova, 2014b). Statistics models: $\mathrm{CMIN}=14.545 ; p=.485 ; \mathrm{CMIN} / \mathrm{df}=0.970$; $\mathrm{AGFI}=0.951$; GFI $=0.987$; CFI $=1.000$; RMSEA $=0.000$. F1 - indicators of the child's relationship to objects in the material world. Thick arrows indicate regression of communication in the child-parent relationship and regression in the child's relationship to objects in the material world; double-edged arrows indicate correlations with relationship styles in the family; figures are the regression weights of the correlations indicated by the arrows. 
dal activities was also the average degree $(M=2.0)$, which indicates a sufficiently developed strategy of interaction with the subject-object world: the child weren't restricted to the random commission of any offense but repeated it over and over again. This finding confirms the analysis and the representation of children's vandal behavior in the primary school environment: observation of students in the educational environment and expert assessment from teachers showed that about $27 \%$ of respondents committed acts of a destructive or transformative nature at least once. Of these, about $10 \%$ showed vandal behavior systematically.

Studies of the role of the family in the formation of the child's interactions with objects in the surrounding space, including vandal actions, were carried out by structural modeling. As a result of the application of mathematical and statistical methods, a model was obtained that contains parameters that characterize the system of parent-child relations and indicators that reveal the child's relationship to the world of things (Figure 1).

Thus, the most connected of all diagnosed features of the interaction of the child of primary school age with objects in the surrounding area were a preference for others' things, a tendency to systematically update the child's own objects and to depreciate "old" objects, and a tendency to destroy or otherwise vandalize objects.

\section{Adolescents}

A two-step cluster analysis $(p<.010)$ was used to clarify the extent of vandal behavior in this age group; the analysis detected the presence in our sample of three subgroups. The first cluster (64\% of the respondents) included teenagers whose median propensity for vandalism was at the normative (low) level with a single upper limit of normal for individual respondents on various scales exceeding regulatory limits by $1-2$ points. In the second cluster were the $23 \%$ of respondents whose median propensity for vandalism was within the normative range but with a single upper limit of normal for individual respondents exceeding regulatory limits by 5-10 points. The third cluster included the $13 \%$ of respondents whose median propensity for vandalism clearly exceeded the statutory limit; the propensity of many of these respondents exceeded the upper limit of normal by 15 points or more. These subgroups were subsequently compared with each other with respect to the strength of their characteristics of vandal activity (on the Mann-Whitney test).

The statistics showed that the teenagers in the first and second groups with standard indicators of propensity for vandalism did not differ significantly from each other. However, there were substantial differences in the adolescents in the second and third groups on the following variables: a harmonious personality $(U=34.5 ; p=.025)$; resistance in difficult situations $(U=33.0 ; p=.022)$, sense of identity $(U=39.5 ; p=.051)$. In the group with a high propensity for vandalism the rate of vandal activity was significantly higher than that for the normative sample. This finding can be explained by the fact that for teenagers the mechanism for development is self-assessment and awareness of the outward result of specific actions. Thus, damaging others' property or public property can contribute to an increased understanding of themselves and their capabilities; it provides training for appropriate behavior in difficult situations and a generally positive assessment of themselves through overcoming social norms and prohibitions. 
As a result of our analysis and synthesis of existing approaches, we can suggest that the sovereignty of psychological space and the orientation of teenagers on certain personality characteristics can act as preconditions for the formation of readiness to commit acts of vandal behavior. For the mathematical and statistical treatment of data we used multivariate regression analysis; the general parameters of the resulting model were: $F=12.4 ; p=.000 ; R^{2}=10.3 \%$. As a dependent variable we chose the overall motivational readiness of teenagers to commit vandal actions; such actions cause changes in the sovereignty of the physical body $(\beta=0.202$; $p=.005)$ and the sovereignty of the world of things $(\beta=-0.108 ; p=.012)$.

Thus, it can be assumed that the expression of teenagers' motivational readiness to commit vandal acts is initiated because of the aborted sovereignty of psychological space and thus is a violation of ideas about the acceptable limits of this activity. Teenagers who have some problems understanding their own bodies and physiological needs and are overall dissatisfied with themselves are likely to choose a behavior that involves causing harm to other people's property. Perhaps a compensatory mechanism is triggered that arises from internal discontent with themselves and their existence in the subject-object environment. In addition, deprivation of sovereignty of the world of things also provokes vandal activity. Problems with the definition of the boundaries of others' property lead to unauthorized use. This feature may form in teenagers because of a lack of personal belongings in the sensitive period for the ontogenesis of this behavior. And if the first cause for readiness to engage in vandal behavior and even for some awareness in choosing such behavior is a teenager's compensatory reactions and defensive positions, the second cause is closely related to a violation in the ontogeny of adequate ideas about the world and a person's place in it.

\section{Young adults}

The young-adult sample was also subjected to a two-step procedure of cluster analysis on the diagnostic data questionnaire Motives for Vandal Behavior $(p<.050)$. As a result, three clusters were identified. The first cluster included the $56 \%$ of respondents whose median propensity for vandalism was at the normative (low) level with a single upper limit of normal for individual respondents on various scales exceeding regulatory limits by 1-2 points. In the second cluster were the $35 \%$ of respondents whose median propensity for vandalism was at the upper end of the normative range with many individual respondents exceeding the regulatory limits by over $9-10$ points. In the third cluster were the $9 \%$ of respondents whose median propensity for vandalism clearly exceeded the statutory limit; the propensity of many of these respondents exceeded the upper limit of normal by 15 points or more.

To identify features of the representation parameters of the subjectivity of the respondents with regard to their propensity for vandalism, we conducted a comparative analysis of selected clusters using the Kruskal-Wallis test with a refining pairwise comparison to the Mann-Whitney test. Nonparametric criteria were used in connection with the disequilibrium number of comparison groups, and therefore there are substantial differences in dispersions. In general, the respondents in the third cluster, with a high propensity for vandal acts, had most of the char- 
acteristics of vandal activity at significantly lower levels than did respondents in the other groups. Thus, a smaller number were aware of their own personalities $(H=6.1 ; p=.048)$, had nontypical internal accounting requirements and external conditions in the construction of behavior $(H=10.2 ; p=.006)$, experienced dissonance in the relationship of themselves and the world around $(H=6.6 ; p=.037)$, and lacked focus on the achievement of high results $(H=5.8 ; p=.057)$. In addition, pairwise comparisons of those in the third cluster and those in the second cluster, whose propensity to commit vandal acts was expressed to a middle degree, revealed a significant difference in the parameter diversity and interest in life $(U=2040.5$; $p=.032$ ), which was less characteristic for the third group.

To clarify the nature of the relationship characteristics of vandal activity and motivational readiness to engage in vandal behavior in the group with a high propensity for vandalism, we conducted a correlation analysis (Spearman's rank coefficient). We found that mercenary motives for vandalism, which involve the commission of such acts for personal gain, were linked to the desire for outstanding achievements in various fields $(r=0.457 ; p=.025)$. It can be assumed that a business model is adopted by some people as a valid option because of their high need for approval, ambitious goals, or tendency to perfectionism. In this case, the person is ready to use any means to achieve the desired outcome. Protester vandalism, caused by the desire to register one's disagreement with something, was negatively correlated with initiative $(r=-0.569 ; p=.004)$, ability to manage emotions, desires, and actions $(r=-0.471 ; p=.020)$, positive emotional tone $(r=-0.526 ; p=.008)$, and willpower $(r=-0.412 ; p=.046)$. Or perhaps the choice of an antisocial activity model that was detrimental to the property of others or to public property resulted from having a nihilistic outlook as well as from failing to regulate and control one's own behavior. Vandalism caused by boredom, the desire to occupy oneself with something, had a direct correlation relationship with initiative $(r=-0.440 ; p=.032)$. A high need to realize oneself can give rise to a misunderstanding of a situation, and the result is destructive vandal actions committed for temporary distraction and entertainment.

The analysis of the young adults' motivational readiness to commit vandal acts revealed ten possible motives. One of the most prevalent was the motive of curiosity; This motive was present in about about $21 \%$ of the respondents; they had a pronounced tendency to choose vandalism as a way of studying the world and themselves. In our analysis of curiosity as a motive in our group of respondents we formed a regression model that explains it through various properties of the respondents' subjectivity (model parameters: $F=8.0 ; p=.001 ; R^{2}=80 \%$ ). These data describe the "curiosity vandals" as being emotionally positive, active, and sociable $(\beta=0.705 ; p=.013)$, capable of self-control $(\beta=0.984 ; p=.002)$, but not fully accepting of themselves as a whole person $(\beta=-0.667 ; p=.010)$ and not agreeing with the terms and circumstances of their life $(\beta=-0.525 ; p=.005)$. In addition, they are not capable of volitional effort in everyday life $(\beta=-1.000 ; p=.001)$, they lack initiative ( $\beta=-0.842 ; p=.004)$, and the most complete realization of their personal potential occurs in stressful emergency situations $(\beta=0.894 ; p=.002)$. This characteristic leads them to take risks in potentially contentious interactions with the environment. They choose vandal actions as a convenient way to get information about themselves from the outside world. 


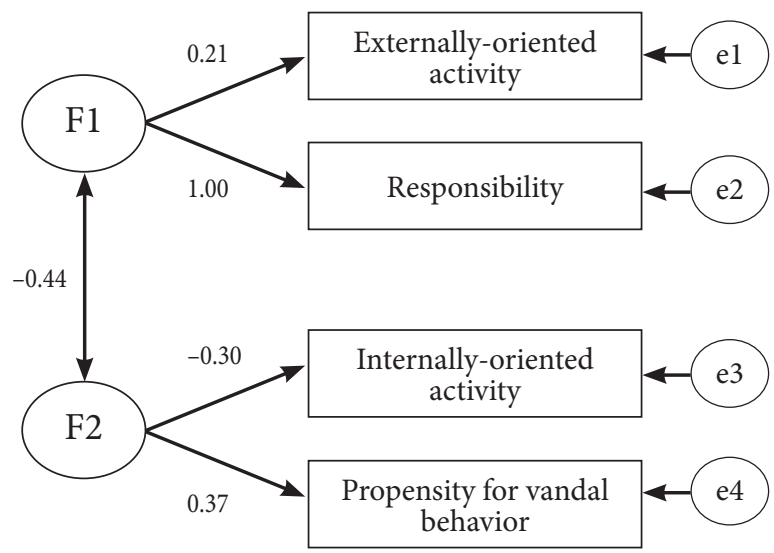

Figure 2. Measurement model of the relationships between propensity for vandal behavior and the orientation of the respondents with normative behavior on certain personality characteristics . Statistics models: $\mathrm{CMIN}=0.152, p=.927$; CMIN / $\mathrm{df}=0.076 ; \mathrm{AGFI}=0.996 ; \mathrm{GFI}=0.999 ; \mathrm{RMSEA}=0.000 ; \mathrm{F} 1-$ indicators of vandalism in the external world, F2 - indicators of vandal activity in the person. Thick arrows indicate regression in communication parameters; figures are the regression weights of the correlations indicated by the arrows.

The results showed a complex subject-personal determination of vandal behavior in the young adults and suggest that they not only can destroy and harm the subject-material environment by such actions but can use such behavior as a tool, a means of implementing cognitive activity aimed at themselves, in order to better understand their own "I", including in the system of social relationships.

The determination mechanisms of vandal behavior in the young adults were identified by using structural models. A statistical procedure included two contrast groups of these respondents: those with a strong propensity to commit vandal actions and those who lack such a propensityThe resulting models allow us to describe the direction activity (to the outside world or to oneself) in the context of readiness to harm someone else's property or public property and taking responsibility for this activity. Thus, in the group of respondents with normative behavior, activity had both vector directions: to the outside world and to the subject, and the respondents expressed willingness to take responsibility for their actions and results. Accepting responsibility in this way leads to activation of work on selfdevelopment and self-improvement (Figure 2). Vandal actions then become unnecessary because the transformation is internal and subject-oriented.

The group of young adults with a strong willingness to commit vandal behavior did not have an internal implementation of vector activity, preferring an externally oriented (environmental) expression of themselves. At the same time they are ready to take responsibility for their actions, and the vandal activity was demonstrative and of an oppositional character. The results of such actions are not analyzed, are not internalized, and do not lead to internal changes (Figure 3).

Thus, young adulthood was found to be a period of increased tendencies to commit vandal actions. In addition to the internal / subjective or personal factor, the young adults were susceptible to social pressure in the environment and tended 


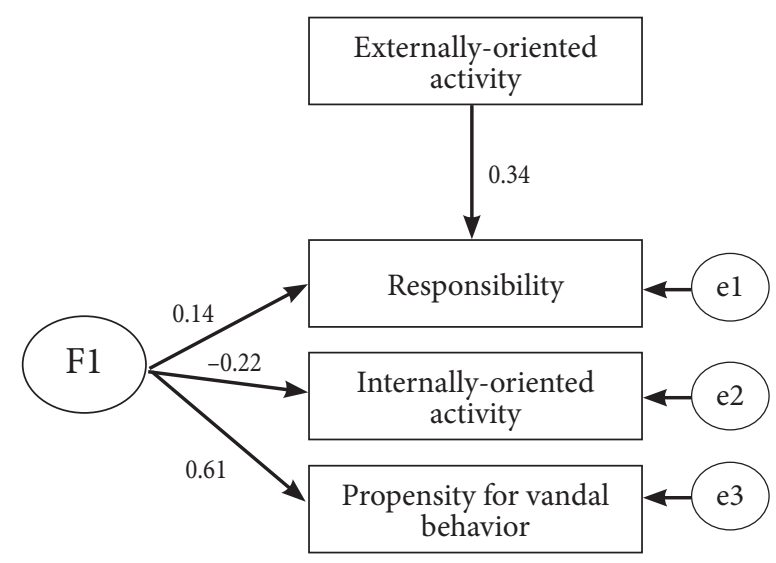

Figure 3. Measurement model of the relationship between deviant behavior and the respondents' propensity for vandal behavior and orientation on certain personality characteristics (Vorobyeva \& Krivoshchekova, 2014). Statistics models: $\mathrm{CMIN}=0.131 ; p=.936 ; \mathrm{CMIN} / \mathrm{df}=0.066 ; \mathrm{AGFI}=.983 ; \mathrm{GFI}=0.997 ; \mathrm{RMSEA}=0.000$. F1 - indicators of specific activity. Thick arrows indicate regression in communication parameters; figures are the regression weights of the correlations indicated by the arrows.

to choose vandalism as a means of identifying themselves with their generation in opposition to the adult world. A more detailed study (Vorobyeva \& Krivoshchekova, 2014) of the psychological readiness of young men to damage someone else's property or public property has shown that the key phenomenon that triggers the mechanism of choosing vandal behavior is a disordered orientation toward activity. Having the ability to work on this problem and change oneself can minimize the risk of vandalism in young adulthood.

\section{Discussion}

According to the study. the preschool children who in their actions demonstrated elements of vandal behavior had difficulty communicating with peers and adults, were impulsive, often reacted inappropriately in communicative situations (were aggressive or, conversely, were too shy), poorly understood themselves and the motives for their actions, and may have had a low level of education for their age.

Some importance is attached to building a culture of interaction with the objective world through the parent-child relationship. Thus, a mother's concentration of her efforts on family matters and renunciation of limiting her own interests and activities solely to economic concerns allow due consideration of the mother for the child and the child's education, transfer of knowledge, and formation of the social, activity, intellectual, and value spheres of the child's personality. At the same time, involving the father in this process, setting limits on the "power" of the parents to restrict the child's possibilities, setting clear rules of authority, as well as providing a positive emotional background allow the child to acquire the optimum level of independence and do not suppress the child's practical activity but form an understanding of the limits of its manifestation. 
The preconditions for the vandal behavior of preschoolers are excessive distancing from them, suppressing their will and practical activity, and not making reasonable demands of them or constructive contact with them. These preconditions can be the result of lack of interest, indifference toward the child, or parents' lack of self-confidence in their role as educators.

Adequate behavioral expectations are formed in families with a high level of acceptance, optimal emotional contact, and optimal dependence on the family; these families also provide adequate but nonexcessive care for their child. The choice of passive strategies can lead parents to refuse to have contact with the child, to have a fear of offending the child, and to exhibit a strong sense of self-sacrifice. When a child commits acts of elements of vandalism, that behavior contributes to a high level of parental evasion of contact with the child, a significant suppression of the child's will and attempts to overcome the child's resistance, and the presence of maternal feelings of dependency and lack of independence. At the same time securing pro-social models promotes rigor, the desire to accelerate the development of the child, and an egalitarian relationship between the parents and the child.

Pupils' orientation toward things that do not belong to them cannot be considered exclusively as a negative aspect of their personality. For example, young children may choose others' toys (in the presence of their own), but in this case curiosity and the novelty effect satisfy them if parents use pro-social behavior strategies, such as making requests, cooperating, sharing. However, there are opposite options-deception, taking possession of another's things, causing damage-that are more closely associated with the kinds of negative behavioral patterns that a can demonstrate in relation to objects in the environment. Our analysis showed that the causes of these patterns are specific features of the parent-child relationship, such as a lack of emotional contact between the parent and the child, the distancing of the parent from the child, and parental rejection of the child. Accordingly, we can assume that on the one hand the actions of the child may be dictated by the objective need, significant for his age group, for things the parents do not buy for a variety of reasons. On the other hand, numerous studies show that when these types of parental behavior occur, the child has for the most part already been provided with everything necessary but feels the need not for material objects but for the attention and participation of the parents. In this connection, the preference for others' things and taking them without the permission of the owner can be a kind of compensatory response to a rift in the family and, in some cases, can be a way to attract attention. It is as if the child at an early age replaces a system of social relationsespecially the one that was supposed to be a priori emotionally comfortable and safe, more predictable, and already well established action systemwith material objects in the previous age periods.

The child's desire to systematically update the objective world on the one hand manifests itself in regular requests for new things and on the other hand accompanies the inadequate treatment of already-owned objects. Thus, the child loses, breaks, gives away, or just does not use the thing requested and at the same time articulates new requests. Such a strategy expresses the symbiotic position of the parent and the child, which manifests itself in the parent's effort to meet all the needs of the child in order to protect the child from troubles and difficulties. The more parents are focused on creating comfort for the child to meet the world through a 
wide variety of needs for a diversity of things, the less meaningful these things are for the child. As a result, the child may have no realistic idea of the value of the objects and the possibilities for their acquisition.

Preschoolers' tendency to destruction and damage of items often appear as unconscious vandal acts. In this case, the children are well aware of the process by which these acts occur and most likely can predict the result but do not realize that such behavior is proscribed because the objects are not their personal property. Often, such objects are identified by pupils as "unnecessary," and they do not accord them any importance for society, a group, or an individual. Such a view occurs when the parents maintain a maximum distance from their children. Probably the lack of systematic interaction between parents and children, which not only forms values and beliefs about the world but also generates awareness of the child's place in it, leads children to misunderstand the borders of their actions. As a result, forms of interaction with the outside world, including the world of things, are formed spontaneously in a child under the influence of situational factors that can lead to feelings of mistrust and inferiority. The vandal actions of these children are performed systematically and unreflectingly. The children are not aware of the social unacceptability of their actions, and the motivational basis of this behavior depends on the experience of interacting with the world that they received in the course of their development.

Thus, vandal behavior is most characteristic of adolescence and young adulthood but has a long genesisand forms from the early stages of ontogeny. Younger children who damage someone else's property or public property are not always aware of the negative social meaning of their actions, but in this period the stable installation of the intentional infliction of harm to material objects can take place. Personality development is due largely to the social factor, the system of parentchild relationships remains a key element of it in the period of primary school age. It is precisely in these conditions that children's pictures of the world are determined by the value-semantic aspect of material objects and socially acceptable ways of interacting with them as well as by the formation of mechanisms for reflecting the social characteristics of children through their own things and attitudes toward them. Destructive parent-child relationships negatively affect the development of children and form their misconceptions about themselves and their place in the system of social relations and in their relations with the objects of the material world. Thus, excessive distance from or even rejection of the child initiates certain behavioral patterns of destructive actions of a compensatory-demonstrative nature in relation to other people's things. Conversely, an excessively symbiotic relationship with a child devalues the physical environment, both the child's own things and objects belonging to the society or other people.

\section{Conclusion}

Based on the results of the study the mechanism for the formation of vandal activity can be suggested it has the following roots in the genesis of age development.. Because of the child's special relationship with significant adults, the nature of the child's interaction with the subject environment is determined largely by the parent-child relationship (Lisina, 1997; Rozhdestvenskay, 2002). When a child of 
preschool age commits vandal actions toward others' property or public property, the child is guided mainly by an emotional outburst or negative feelings (jealousy, desire to avenge), and the regulation of the conduct does not involve the deep reflexes. Excessive control, lack of requirements, and subject-object variants of parents' and caregivers' relationships with preschoolerslead to deformation of ideas about acceptable limits of the implementation of activity, which in turn contributes to children's choosing vandal behavior as a strategy for meeting urgent needs. In the early school years vandal activity is latent. Changing the social situation of development leads to children's experiencing the effect of novelty. They are dominated by social motives for educational activity and an acute sense of responsibility for behavior; they are important in the eyes of their reference groups of adults and peers (Davydov, 1990). This situation creates conditions for control and self-control and makes it almost impossible for the emergence of actual forms of vandalism. However, in this period the internal readiness of the child to consciously choose vandal behavior in the future as a way to solve personal problems forms. Because of the conservation role of parents in shaping the boundaries of the permissible activity of the child, the presence of disharmonious parenting styles in a family creates the preconditions for the emergence of psychological readiness to consciously choose vandal actions.

Vandal actions are most evident among teens (Vatova, 2000); at this periodin the normal development of the personality there are two options for the initiation of such a deviation. In the first case, vandalism is a result of experimentation with the social, objective environment or the person's own capabilities and is characterized by situational poverty; such behavior gradually loses its relevance for the maturing personality. In the second case, vandalism is a manifestation of conformity: vandal acts are a way to maintain social acceptance and identification of a teenager in a reference group. Here vandalism is not an aim itself; for a teenager it acts as an element or type of joint activity that creates a sense of belonging to the community. Teenagers who have not formed at earlier stages of development the necessary social and reflexive skills because of external conditions compensate for their powerlessness and incompetence in the social sphere by making a destructive impact on the objective environment for the purpose of self-knowledge his experiences, opportunities and the other's relationships with him and his activities.. Thus, vandal activity allows teenagers to indirectly perform the basic tasks of their age in order to form a self-image, but it simultaneously reinforces a deviant pattern of behavior.

In the next age period-young adulthood-this model is fixed and compounded; young adults continue to know themselves and their capabilities through the transformation of the environment, including the unauthorized destruction of its facilities. The energy that goes into normative development in the formation of self-knowledge and is based on the trajectory of future life here is replaced by externally-oriented activity, including activity of a destructive nature. In addition, those young adults who previously chose vandalism because of group pressure reinforce this behavior through their inclusion in youth subcultures, many of which directly or indirectly commit vandal actions for ideological reasons. 


\section{Acknowledgments}

This study was conducted with funding from a grant from the President of the Russian Federation for state support of young Russian scientists and PhDs: MK4245.2013.6.

\section{References}

Allen, V., \& Greenberger, D. (1978). An aesthetic theory of vandalism. Crime and Delinquency, 24(3), 309-321. doi: 10.1177/001112877802400305

Ceccato, V., \& Haining, R. (2005). Assessing the geography of vandalism: Evidence from a Swedish city. Urban Studies, 42(9), 1637-1656. doi: 10.1080/00420980500185645

Coffield, F. (1991). Vandalism and graffiti: The state of the art. London: Calouste Gulbenkian Foundation.

Cohen, S. (1973). Property destruction: Motives and meanings. In C. Ward (Ed.), Vandalism (pp. 23-53). New York: Van Nostrand Reinhold.

Davydov, V. V. (Ed.). (1990). Psihologicheskoe razvitie mladshih shkolnikov: Eksperimentalnoe psihologicheskoe issledovanie [The mental development of children of primary school: Experimental psychological research]. Moscow: Pedagogics.

Elliott, D. S., Huizinga, D., \& Menard, S. (1989). Multiple problem youth: Delinquency, drugs, and mental health problems. New York: Springer-Verlag. doi: 10.1007/978-1-4613-9637-6

Goldstein, A. (1996). The psychology of vandalism. New York: Springer Science+Business Media. doi: 10.1007/978-1-4899-0176-7

Gurova, O. V. (2014). Shkolny graphichesky vandalism kak sposob realizacii potrebnosti v aktivnosti v podrastkovom vozraste [School graphic vandalism as a way to address the need for activity in adolescence]. In Psihologiy i pedagogika $v$ sovremennom mire: Vizovii i resheniy [Psychology and pedagogy in the modern world: Challenges and solutions] (pp. 2730). (20th International Scientific-Practical Conference for Graduate Students and Young Scientists.) Moscow: Moscow Research Center for Psychology and Pedagogy.

Harina, E. N. (2005). Rassledovanie vandalisma: Kriminalisticheskie i ugolovno-pravoviye aspekty [The investigation of vandalism: Forensic and criminal-legal aspects] (Unpublished doctoral dissertation in law). Moscow: Lomonosov Moscow State University.

Kalmikova, E. S. (2013). Psihologo-pedagogicheskiy profilaktika podrostkovogo vandalisma [Psychopedagogical prevention of teenagers' vandalism] (Unpublished doctoral dissertation in pedagogical sciences). Moscow Pedagogical State University, Moscow.

Le Blanc, M., \& Freshette, M. (1988). Male criminal activity from childhood through youth. New York: Springer-Verlag.

Lisina, M. I. (1997). Obshchenie, lichnost i psihika rebenka [Communication, personality, and the psyche of a child]. Moscow, Voronezh: Institute of Applied Psychology, NPO; Modek.

Pashutina, O. S. (2009). Vandalism kak prestuplenie protiv obshchestvennogo porydka [Vandalism as a crime against public order] (Unpublished doctoral dissertation in law). Rostov-onDon, Russia: Rostov Law Institute of the Interior Ministry of the Russian Federation.

Patrusheva, Z. V. (2010). Osnovniy napravleniy profilaktiki vandalisma nesovershennoletnih v otechestvennoy i zarubezhnoy pedagogiki [The main strategies for preventing juvenile vandalism in domestic and foreign pedagogy]. Scientific Problems of Humanities Research, 12, 172-177.

Pirozhkov, V. F. (1994). The laws of the criminal world of youth: Criminal subculture. Tver, Russia: Priz. 
Rozhdestvenskay, N. A. (2002). Negarmonichniy stily semeinogo vospitaniy $i$ vospriytiy roditeliymy svoih detey [Inharmonious styles of family education and parent perceptions of their children]. Bulletin of Moscow University, 2, 48-53.

Samokhina, L. M. (2007). Preduprezhdenie podrostkovogo vandalisma [Warning of teenagers' vandalism]. Bulletin of Chelyabinsk State University, 2, 108-113.

Shuruhnov, V. A. (2002). Rassledovanie vandalisma [The investigation of vandalism] (Unpublished doctoral dissertation in law). Moscow: Academy of Management of the Interior Ministry of Russia. .

Shvets, A. B., \& Yakovlev, A. N. (2011). Nekotorye osobennosty geograficheskogo isucheniy rsonansnyh sluchaev vandalisma $v$ sovremennom Krymy [Some features of the geographical study of the response to cases of vandalism in modern Crimea]. Scientific Notes of Taurida National University named after V. I. Vernadsky. Series: Geography, 24(63), 267-276.

Skorokhodova, A. S. (1999). Vandalism. Journal of Sociology, 34, 49-67.

Thompson, K., Offler, N., Hirsch, L., Every, D., Thomas, M. J., \& Dawson, D. (2012). From broken windows to a renovated research agenda: A review of the literature on vandalism and graffiti in the rail industry. Transportation Research Part A, 46, 1280-1290. doi: 10.1016/j. tra.2012.04.002

Tserkovnikova, N. G. (2011). Podrostkoviy vandalism kak psihologo-pedagogicheskay problema [Teenagers' vandalism as a psychological and pedagogical problem]. Collection of Scientific Works World, 15(4), 19-20.

Vatova, L. S. (2000). Psihologicheskie prichiny i usloviy vosniknoveniy podrostkovogo vandalisma [Psychological causes and conditions of teenagers' vandalism] (Unpublished doctoral dissertation in psychological sciences). Kaluga, Russia: Kaluga State Pedagogical University.

Vatova, L. S. (2007). Socialno-psihologicheskiy osnovaniy molodezhnogo vandalisma i ego profilaktika [Sociopsychological foundations of youth vandalism and its prevention]. Moscow: National Education, MPSI.

Vorobyeva, I. V., \& Krivoshchekova, M. S. (2014) Youth vandalism as a form of personal activity in interaction with the environment. Paper presented at the 28th International Congress of Applied Psychology (ICAP), Paris. Retrieved from https://b-com.mci-group.com/Abstract/ Statistics/AbstractStatisticsViewPage.aspx?AbstractID $=184426$

Vorobyeva, I. V., \& Kruzhkova, O. V. (2012). Psihologiy gorodskoy sredy [Psychology of the urban environment]. Ekaterinburg, Russia: Russian State Professional-Pedagogical University.

Vorobyeva, I. V., \& Kruzhkova, O. V. (2014a). Psihologiy vandalnogo povedeniy [The psychology of vandal behavior]. Ekaterinburg, Russia: Ural State Pedagogical University.

Vorobyeva, I. V., \& Kruzhkova, O. V. (2014b). Rol detsko-roditilskih otnosheniy v formirovanii gotovnosti $\mathrm{k}$ vandalnomy povedeniu $\mathrm{v}$ mladshem shkolnom vosraste [The role of the parent-child relationship in the formation of readiness to engage in vandal behavior in middle childhood]. Bulletin of Tyumen State University. Series: Pedagogy. Psychology, 9, 230-237.

Original manuscript received December 01, 2014

Revised manuscript accepted March 03, 2015

First published online March 31, 2015 